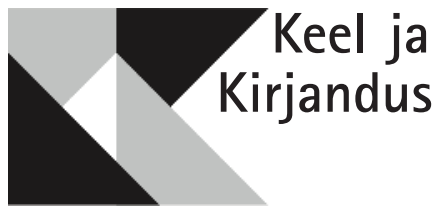

\title{
KAS JAKOB LIIV KIRJUTAS ESIMESED EESTIKEELSED SONETID?*
}

\author{
REBEKKA LOTMAN
}

\section{Sissejuhatuseks}

$J$

akob Liivi positsioon eesti kirjandusloos on üsna tagasihoidlik. Enamasti peetakse teda usinaks autoriks, kelle mahukal loomingul suurem väärtus või sügavam tähendus puudub. Sageli ongi liiga rohket avaldamist nimetatud ühe luuletuste taset nõrgendanud tegurina. Näiteks Johannes Aavik leiab, et just seetõttu on Jakob Liivi luules paiguti kannatanud väljenduse tihedus, sisuline sügavus ning tundedki kõlavad luuleridades šabloonselt ja üldsõnaliselt. „See on kui ühe järve pind, kus sünnib harva suuri lainetusi ja kuhu paistab 90-date aastate hall ja natuke aate- ning tundekahvatu taevas," märgib Aavik (1929: 14-15).

Positiivsed hinnangud keskenduvad ennekõike Jakob Liivi varasema luule oma ajastu kontekstis puhtale värsitehnikale ja keelele. Enim hindab luuletajat tema noorem kolleeg Henrik Visnapuu, kelle sulest pärineb põhjalikem autori elu ja luule analüüs (Visnapuu 1921: 51-79). Mitmes plaanis vastandab ta Jakob Liivi tema nooremale vennale Juhan Liivile: kui Jakobi loomingut iseloomustab Visnapuu sõnul apolliline selgus, siis Juhani luule on dionüüsiline - ebamäärane, hämar, amorfne. „Nii lohakas kui vend Juhan värsitehnika ja keele puhtuse alal on, niivõrd hoolikas on Jakob. Jakob Liivil on

* Autor tänab Märt Väljatagat, kes juhtis tähelepanu mitmele olulisele asjaolule, ja samuti retsensenti. 
keele- ja vormitunnet, mis vennal puudus...." (Visnapuu 1921: 76). Kuid ka positiivseid kirjutisi vanemast Liivist saadavad sageli nendingud, et ta ei ole eesti luulesse toonud midagi uut. Mitmel puhul räägitakse otsesõnu tema andetusest. ${ }^{1} \mathrm{Ka}$ on teda täiesti alusetult süüdistatud plagiaadis. ${ }^{2}$

Nagu on nende luulet peetud vastandlikuks, on kontrastne ka Jakob Liivi positsioon noorema venna Juhani kõrval, millega kaasnevalt on talle omistatud kibestumustki. Visnapuu hinnangul ongi Juhan Liivi sedavõrd oluline koht eesti luules põhjustanud Jakob Liivi varjujäämise: „Oma noorema venna Juhanile, kelle laulude meeletu valu ja uus igatsus noorema sugupõlve igatsustele rohkem vastas, võlgnebki Jakob Liiv tänu, et ta luuletajana kõrvalisele kohale on surut" (Visnapuu 1921: 54).

Ehkki Jakob Liiv on kindlasti XIX sajandi eesti tähtsaim sonetiautor ning mõnigi kriitik on seda rõhutanud, ${ }^{3}$ ei ole seni ainsas eesti sonetimonograafias, Bernard Kangro „Eesti soneti ajaloos”, tema tähtsust sonetistina märgitud üldiselt piirdub Kangro Liivi nimetamisega loeteludes, ühe nimena teiste ajastu sonetistide kõrval.

Käesolevas artiklis tuuakse välja kaks Jakob Liivi sonetti, mis luulekogudes avaldatud dateeringute põhjal on üldse esimesed eestikeelsed sonetid, vaagides võimalikke argumente nende esmasuse kasuks ja kahjuks ning heites pilgu nii kõnealustele sonettidele kui ka autori elule antud luuletuste kirjutamise perioodil. Põgusalt peatutakse ka Jakob Liivi tegevusel kirjanduselu arendamisel. Seega on artikli eesmärk vaadelda autori loomingut kultuuriloolisest aspektist.

\section{Esimesed eestikeelsed sonetid. Käibiv lähenemine}

Eesti sonetil võib eristada vähemalt kolme sünnikuupäeva. Esimesed sonetid Eesti pinnal kirjutas sakslane Reiner Brockmann (1609-1647), Rostocki ülikoolis hariduse omandanud Tallinna gümnaasiumi kreeka ja ladina keele õpetaja, kelle loomingust leiab seitse saksakeelset sonetti (Brockmann 2000: 81-91). Esimene eesti soost sonetist on Kristian Jaak Peterson (1801-1822), kes oma surma-aastal kirjutas samuti saksakeelse soneti, ${ }^{4}$ mis ilmus esmakordselt küll 1823. aastal väljaandes „Zeitung für die elegante Welt” (Peter-

1 Vrd nt Jakob Liivi luulekogumikku „Jakob Liiw’i kirjatööd. 1. anne” (Liiv 1906) kohta ajakirjas Eesti Kirjandus ilmunud retsensiooni, kus sedastatakse: „Jakob Liiv ei ole suur vaim. Uusi teesid ei ava tema maailmale, ega oma sugurahvalegi" (Jõgever 1907: 27) ning teise osa ilmudes märgib sama toimetaja, et midagi lisada pole, kuna „Jakob Liivi luuleand ei ole suur" (Jõgever 1910: 161-162).

2 Samas „Jakob Liiwi kirjatööde” 2. osa arvustuses märgib Jõgever, et lugulaulu „Kõrbelõvi” puhul on tegelikult tegu tõlkega, kus autor on „unustanud” algupärase allika märkida (Jõgever 1910: 162). Sellele vastab luuletaja, et kõnealuses kaheksast pikast laulust koosnevas loos on vaid kolmandas kasutatud araabia muinasjutu motiive ning seal on ka allviide „Arabia muinasjutt” (Liiv 1910: 270).

${ }^{3}$ Vrd nt Visnapuu 1921: 78-79; Kuningas 1960: 32.

4 Tegu on 5-jalalise jambiga, mille riimiskeemiks AbbA / CddC / EFG / EFG (Peterson 1976: 90-91); sonetti on eestindatud Betti Alver (Peterson 1976: 93), kusjuures Alveri eestinduses on tegu 5+5+3+3 luuletusega skeemiga AxbbA / XCddC / EFG / EFG ehk lisatud on üks värss ning ühe erandiga on kõik värsid 6-jalalised jambid (Peterson 1961: 1047); samuti Ants Oras, kes järgib värsimõõtu, ent mitte kolmikute riimiskeemi - $\mathrm{Cde} / \mathrm{CeD}$ (Oras 1966: 67), ning Indrek Hirv, kes järgib küll autori stroofi- ja riimiskeemi, kuid samuti on valinud 6-jalalise jambi (Hirv 2000: 173). 
son 1823), aga need luuletused taasavastati alles 1961. aastal (vt Peterson 1961: 1046-1047; Lepik 1961: 1047-1048; Oras 1966: 67-68).

Ning kolmandaks, eestikeelse soneti sünd. Peamine - ja tihti ainus - tõsiasi eesti soneti kohta, millele Bernard Kangro magistritöös „Eesti sonetiajalugu” viidatakse, on tema leid, et „esimene eestikeelne sonett, M. J. Eiseni „Õnnesoov isamaale” ilmus 30. juunil 1881. a. Eiseni enda koostatud luuleantoloogias „Eesti luuletused”" (Kangro 1938: 30).5 Nii tuuakse see välja näiteks Jaak Põldmäe „Eesti värsiõpetuses” (1978: 221) ja eesti soneti antoloogia „Sajandi sada sonetti” eessõnas (Mäger 1986: 8, „Õnnesoov isamaale” on ühtlasi raamatu avaluuletus). Samuti ingliskeelses eesti soneti käsitluses, artiklis „Estonian Sonnet” refereerib filoloog William Kleesman Matthews Kangro sonetiuurimust (Matthews 1946: 160-161). Arusaam, et enne Eisenit ühtegi sonetti ei ole kirjutatud, on niivõrd juurdunud, et Lydia Koidula tekstikriitilises väljaandes paigutab koostaja Eva Aaver Koidula soneti „Omal teul” ilmumisaasta järgi 1881. aastasse märkusega, et „luuletuse loomise terminus post quem peaks olema 1881. aasta, varem eesti luules sonetivormi ei esinenud" (Koidula 1969: 614). Küsimus esimesest autorist pole seega tähtsusetu, vaid märkimisväärne komponent kirjandusliku žanri käsitlustes, esmakirjutaja ja esimene sonett pälvivad justkui sümboolse koha kõnealuse žanri juures.

Märkigem veel, et Bernard Kangro lükkas Matthias Johann Eiseni „avastamisega” kõrvale Mihkel Kampmanni „Eesti kirjandusloo peajoontes” ilmunud väite, et esimesteks eestikeelseteks sonettideks on Lydia Koidula „Nad taovad sinu tüve sisse talva" ja "Täis ahastust ja sõda sinu süli” (Kampmann 1933: 82). Kangro sedastas, et Koidula sonettidest esimene trükiti Oleviku lisalehes 1883, nr 39, teine veel hiljem, seega varaseim on Eiseni sonett (Kangro 1936: 270). ${ }^{6}$ Samas möönab Kangro, et Eiseni prioriteet on tinglik ning tegelikeks eestikeelse soneti loojateks peab sonetiuurija ikkagi Lydia Koidulat või Jaan Bergmanni: nimelt ilmus 1881. aasta septembris (Eiseni luuletust sisaldav kogumik tuli trükist juunis) neli Bergmanni sonetti, seeria „Lein ja lootus”, sama aasta detsembris aga Koidula esimene sonett „Omal teul”. Eiseni marginaalset rolli eestikeelse soneti kujunemisel rõhutab asjaolu, et tema loomingus jäi „Õnnesoov isamaale” ainsaks sonetiks, ning Kangro oletusel võis ta selle kirjutamiseks saada inspiratsiooni just oma kunagiselt korterinaabrilt Bergmannilt. Kuivõrd aga Bergmanni sonetiseeria, nagu ka Koidula sonetid, ei ole dateeritud, tõdeb Kangro, et andmete puudumine nende kirjutamisaja kohta ei võimalda jälgida eesti soneti kõige esimesi samme (Kangro 1938: 30). „Nii jääb küsimus, kes kirju t a s esmakordselt eestikeelse soneti, veel lahtiseks. Ometi ei ole aeg esimeste sonettide kirjutamise ja trükkimise vahel küll kuigi pikk olnud, nagu osutab päevakajaline element nendes," tõdeb Bernard Kangro Koidula luuletustele viidates (Kangro 1936: 271).

\section{„Isale”, 1878}

Ometi leidub vähemalt kaks eestikeelset sonetti, mis on dateeritud varasema kuupäevaga kui Eiseni soneti ilmumisaeg, mõlema autoriks Väike-Maarja luuletaja Jakob Liiv (1859-1938).

5 Eisen 1881: 38.

6 Eiseni ja kõnealuste Koidula sonettide vahele mahuvad ka nt 1882. aastal toona 17-aastase Georg Eduard Luiga sulest ilmunud „Eestimaale” (Luiga 1882) ning 1883. aasta esimesest poolest Martin Lipu sonetid „Hallikas” ja „Ära nuta” (Lipp 1883a; 1883b). 
Neist esimene on luuletaja isa juubeliks kirjutatud sonett: 7

\section{Isale 50 aastaseks sündimise päevaks.}

Sull armas isa lendes läinud mööda, Pool-sada aastat aja vooluses -

Kus ringitasid rõõmud Sinu ees

$\mathrm{Ja}$ - mures võtsid oma lapse sööta.

Ei annud Sulle elu ilma tööta.

Mis mulle ohverdasid armastes, -

Et oskan käia kindlais radades

Ja oma hinge teadusega joota.

Nüid võta palgaks lapse hinge tänu, Mis palvetades täna Sulle kannan Ja soovin jätku Sinu aasta-loole.

Oh ela kaua! tunned rändes jänu, Siis elu toeks ennast Sulle annan:

$\mathrm{Su}$ haualt vaatan tänul taeva poole.

Õnnitlussonett „Isale” nägi trükivalgust hiljem kui Eiseni „Õnnesoov isamaale”, ilmudes esmakordselt 1886. aastal Jakob Liivi esikkogus „Wiru-kannel. I. jagu" (Liiv 1886: 27-28), lisaks on sonett antud redaktsioonis ilma daatumita. Niisiis ei reeda siin miski, et tegu võiks olla esimese eestikeelse sonetiga. Seevastu luuleraamatu teises, täiendatud trükis ${ }^{8}$ on luuletuse alla märgitud dateering 1878 - aastaarv, mille põhjal pikeneb eestikeelse soneti vanus kolme aasta võrra. Rääkides esimesest teadaolevast eestikeelsest sonetist, mitte selle retseptsioonist, ei olegi ilmumisajal tähtsust. ${ }^{9}$

Siin tuleb lisada paar olulist märkust. „Isale” on pühendatud kindla kuupäevaga sündmusele, ent luuletaja isal Benjamin Liivil täitus viiskümmend eluaastat 25. jaanuaril 1876, s.t kaks aastat enne luuletuse dateeringut. Aastaarvude sobimatuse kohta saab pakkuda üksnes oletusi. Esiteks võib 1886. aastal ilmunud soneti puhul olla tegu varasema luuletuse edasiarendusega, näiteks isale kaks aastat varem kirjutatud luuletuse sonetivormi valamise või varasema soneti viimistlusega.

Teiseks võiski autor saksakeelsete juhuluuletuste eeskujul, kus sonetid ei olnud haruldased, kirjutada selle soneti paar aastat varem toimunud tähtpäeva auks.

Kolmanda võimalusena autor fabritseeris kuupäeva ning osalt ka pealkirja ja sisu, kirjutades tegelikult soneti 1886. aastal, mil isal täitus kuusküm-

${ }^{7}$ Et artikkel keskendub eestikeelse soneti algusele, on siin ja edaspidi toodud luuletuste esmatrükiversioon.

8 1902. aasta väljaanne „Jakob Liiw'i laulud. Wiru-Kandle I. jagu” on samuti autori koostatud, kõnealuse soneti pealkirjaks on siin „Isale. 50-maks sündimise päevaks” (Liiv 1902: 34).

9 Samuti nagu ei muuda Kristian Jaak Petersoni kohta eesti kirjandusloos see, et ta alles 1905. aastal Gustav Suitsu artikliga „Meie esimene luuletaja” n-ö avastati ja kelle suurem osa luuletusi nägi trükivalgust alles 1922. aastal (vrd Undusk 2001: 19). 
mend eluaastat. Viimase kasuks räägib seegi, et ehkki kolmes autori koostatud raamatus (samuti erinevates luuleantoloogiates) on sonett pühendatud isa 50. sünnipäevale (lisaks nimetatuile ka „Jakob Liiw’i kirjatöödes”, Liiv 1906: 226), ilmus 1929. aasta valikkogus (taas autori koostatud) sonetist versioon „Isale 60. sünnipäevaks”. Siin on ka luuletuse sisus algne „pool-sada aastat” asendatud ajamääratlusega „kuuskümmend aastat” ning soneti all puudub daatum.

Siiski on selline kuupäeva ja/või sisu fabritseerimine luuletuse kolmes esimeses trükis väheusutav: selleks lihtsalt puudus igasugune motiiv. Miks pidanuks Jakob Liiv oma isa 60. sünnipäeval (luuletus ilmus esmakordselt nimelt aastal, mil Benjamin Liiv 60. sünnipäeva tähistas) teda oma luulekogus tervitama 50. sünnipäevale pühendatud sonetiga? Sel juhul olnuks loogiline just vastupidine järjekord, et esmalt avaldab autor sobivasisulise ja „nagu päriselt on” isa 60. sünnipäevale pühendatud luuletuse ning hiljem otsustab kuupäeva ja ühtlasi kõnealuse soneti sündi ajaliselt tahapoole nihutada.

Kuid mis peamine - mingit prioriteedi küsimust eestikeelse soneti osas toona ei olnud. Võimalik, et autor ise ei teadnud, et tolles teises trükis lisatud kuupäev tegi luuletusest varaseima eestikeelse soneti.

Tõde võib asuda ka vahepeal: näiteks võis autor tõepoolest kirjutada soneti algse versiooni 1878. aastal, nagu märgib ka dateering, ent kaheksa aasta jooksul, mis selle ilmumise ja trükkimise vahele jäi, seda lihvida, parandada või koguni ümber kirjutada.

Käsikirjana soneti „Isale” algversioon ilmselt säilinud ei ole, samuti ei leia selle kohta infot Liivi kirjavahetustest ega muudest säilinud dokumentidest. Üks Jakob Liivi kirjutatud käsikiri küll sellest võimalikust esimesest eestikeelsest sonetist Kirjandusmuuseumis on (Jakob Liiv, f 68), kuid antud säilik on ilmselgelt luuletuse hilisem ümberkirjutus - samal lehel on mitu luulekogudes erineva aastaarvuga dateeritud luuletust. Lisaks „Isale” on samal paberil luuletused nii 1884. kui ka 1885. aastast, samuti kaks luuletust, mis Liivi loomingus ongi dateerimata jäänud. Hilisemale ümberkirjutamisele viitab seegi, et käsikirjas ei ole parandusi (v.a see, et sonett „Isale” nagu ka luuletus „Roos” on täies mahus maha tõmmatud). Tõenäoliselt on antud säiliku näol tegu luulekogu mustandiga.

Temaatika kõrval on veel mitu aspekti, mida luuletuses saab siduda või vaadelda ajalises kontekstis. Üheks selliseks on luuletuse konstruktiivne, värsitehniline tasand. Näiteks peab Bernard Kangro üheks argumendiks, millega ta seob Eiseni esimese soneti Bergmanni omadega ning eeldab Eiseni malli võtmist viimaselt, nende riimiskeemide kokkulangevust (Kangro 1938: 30): nelikute skeemideks on süliriim $a b b a / a b b a$, kus naisriim vaheldub meesriimiga $(F m m F / F m m F)$, kolmikute riimiskeemiks on mõlemal autoril $c d c / e d e$, ent Eisenil on tertsetid läbini naisriimilised ( FFF/FFF), Bergmannil aga positsioonil $d$ meesriim $(F m F / F m F) .{ }^{10}$

Meid huvitav periood - varasem trükitud sonett aastast 1881 ja varaseima dateeringuga sonett aastast 1878 - on luuleloos lühike aeg ning esmasust

10 Kangro kirjutab ekslikult, et Bergmanni ja Eiseni sonettide kolmikute riimiskeem on $C D E / C D E$. Nicolas Boileau mõistes, kelle järgi klauslite skeemi ei saa riimiskeemist lahutada ning mees- ja naisriimid peavad vahelduma, poleks korrektne ka Kangro väide, et Eiseni kolmikute riimiskeemid langevad „täiesti ühte Bergmanni 1881. a. avaldatud viie soneti skeemiga" (Kangro 1938: 30). Nimelt eksib Eisen erinevalt Bergmannist klauslite vaheldumise reegli vastu. 
puudutavaid järeldusi on siin võimatu teha. Siiski väärib võimaliku esimese eestikeelse soneti värsikonstruktsioon märkimist.

Jakob Liivi „Isale” riimiskeem - abba/abba/cde/cde - erineb Eiseni ja Bergmanni sonettide riimiskeemidest mitte üksnes klauslite poolest (nelikutes vahelduvad nais- ja meesriimid, kolmikud on läbini naisriimilised: $F m m F$ / $F m m F / F F F / F F F$ ). Liivi tertsettides kasutatud skeem $c d e / c d e$ on levinuim klassikalise itaalia soneti kolmikute riimiskeem, ka soneti looja Giacomo da Lentini loomingus leidub sellist enim. Samuti on näiteks Kreutzwaldi sonett „Der Sommermorgen”11 (Kreutzwald 1953: 322-323) skeemiga abba/abba/ $c d e / c d e$, ent üleni naisriimiline. Seevastu Eiseni ja Bergmanni sonettide $a b b a / a b b a / c d c / e d e$ on hilisem variatsioon, mida algupärases itaalia sonetis ei kasutatud. Ohtralt kohtab sellist skeemi aga saksa romantikute, ka eesti autoreid palju mõjutanud austria poeedi Nikolaus Lenau loomingus.

Värsitehniliselt ei leia midagi erakordset ka Liivi soneti ülejäänud tasanditel. Meetrumilt on „Isale” 5-jalaline jamb, traditsiooniline vaste klassikalise itaalia soneti 11-silbikule nii saksa- kui ka eestikeelses luules. Ajastuomased on värsipiiri ja süntagmaatilise piiri kokkulangemine läbi terve soneti ja ebapuhtad (mööda : sööta : tööta : joota), mitmel puhul puhtflektiivsed (vooluses : radades) riimid. Teemavalikki ei üllata: eestikeelne ilmalik luule sai nimelt suuresti alguse juhuluulest ning taolised pühendussalmid vanematele jt pereliikmetele, sõpradele, mõttekaaslastele ja kolleegidele olid valdavad ka saksa luuletajate seas.

Jakob Liivil on veel teinegi sonett, mis on dateeritud varasema kuupäevaga kui Eiseni „Õnnesoov isamaale”.

\section{„Asjata”, 1880}

Jakob Liivi soneti „Asjata” kirjutamise ajaks on märgitud 1880. aasta. Seegi luuletus ilmus esmakordselt 1906. aastal dateeringuta (Liiv 1906: 9), 1929. aastal aga koos aastanumbri ja lisatud täiendpealkirjaga (Liiv 1929: 74-75).
Asjata
(Hakenrihtri kohtuniku puuris)
Ma raputan ahelad maha, Mis kaua on kannud mu käed Ja võidan kõik vastaste väed, Et sulavad kokku kui vaha.
Nüüd kaugele, kaugele taha Kõik mure ja muljuvad mäed! Ilm, asjata lingusid säed, Teed asjata minule paha! ...
Ma võõraste võimude ette
Ei paenuta elusalt pääd
Kui selle eest kerjama peaksin!

${ }^{11}$ Eesti keeles Ellen Niidu tõlkes „Suvehommik” (Kreutzwald 1953: 331). 
Ehk läheksin tulesse, vette,

Ja otsiksin Manalast hääd,

Kui eneses roomaja teaksin!

1880

Taas on tegu kindla daatumiga seotud sündmusega. Nimelt sattus Jakob Liiv 1880. aastal aresti, kõnealuse kokku seitse päeva kestnud vangipõlve tagamaid kirjeldab autor ka oma mälestustes. Täpse kuupäevaga Liiv oma memuaarides juhtunut ei kaardista, kuid sündmus toimus 1880 . aastal üsna varsti pärast 23. aprilli. 12

Kui ka „Asjata” kannab skeemi $a b b a / a b b a / c d e / c d e$, siis värsimõõdult on see küllaltki ebatraditsiooniline sonett: tegu on kolmikmõõduga, 3-jalalise amfibrahhiga ning just see tekitab küsimusi, kas autor võis selle kirjutada juba 1880. aastal. Peamiselt jäävad Liivil siia perioodi jambid ja trohheused, kolmikmõõtudest leiame ka mõne daktüli: nt on ta markeerinud ühe 3-jalalise daktüli aastanumbriga 1879 (Liiv 1929: 68-69). Ajaliselt määratletud amfibrahhid aga pärinevad tema luules hilisemast ajast, eelkõige 1880 . aastate keskpaigast. Riimidki on sonetis „Asjata” ajastu kohta üsna meisterlikud, autor kasutab siin erinevalt sonetist „Isale” täisriime. Nii võiks öelda, et puhtvärsitehniliselt paigutuks „Asjata” hilisemasse aega, kui seda märgib dateering. Samal ajal ei saa sellegi soneti puhul välistada, et autor seda kirjutamise ja ilmumise vahele jäänud aastail rohkemal või vähemal määral ümber kirjutas. Lisaks on võimalik, et autor lisas aastaarvu tähistamaks mitte kirjutamise, vaid sündmuse enda aega.

\section{Esimeste sonettide aegu}

Jakob Liiv sündis 28. veebruaril 1859 Alatskivil Benjamin (1826-1897) ja Marianne Liivi (1826-1902) neljanda lapsena. Luuletama hakkas Jakob juba poisikesena. Ta meenutab: „Karjapõlves jäin luulehaigeks ja koolipõlves tubakaorjaks, ja neist pahedest pole tänini lahti saanud" (Liiv 1936: 46). Karjapoiss Jakobile õpetas riimimist Lahepera küla noormees Juhanes Saul (Liiv 1936: 34). Esimene sisemine luuletamisimpulss ei tulnud kirjanduslikest eeskujudest, vaid otse elust: õnnetust armastusest ja sotsiaalse lõhe kogemusest. Nimelt olla Jakobi teismeea esimeseks armastuseks olnud rikka kaupmehe

12 1880. aasta jüripäeval asus Jakob Liiv ametisse Väike-Maarja kihelkonnas TriigiUniküla vallakirjutajana (ühtaegu ka Triigi-Avispea vallakooli õpetajana), alustades kohe uuenduste sisseviimisega. „Ma soovitasin vanematele meestele ajalehelugemist ja tellisin „Sakala”, mis siin oli tundmatu. Peremeestele kõnelesin, et enne siinne rahvas jõukamaks ei saa, kui maad saavad kruntideks jagatud ja abitegu mõisale kõrvaldatud, mis enam seadusega kooskõlas ei ole. Ma ei võinud aimatagi, et siinne rahvas mõisa kui autoriteedi peale vaatab," meenutab Liiv, lisades, et tema uuendusnõuded olid rahvale seedimatud, samuti olid Määri mõisaomanikul Zoege von Manteuffelil külas omad usaldusmehed, kes temale kõik vallas räägitu-tehtu edasi kandsid. Sakala tellimise kaudu Carl Robert Jakobsoni ideede viimine külarahva sekka oli Liivi hinnangul põhjuseks, miks mõis tema tegevust taunis ja karistas. „Ei läinud palju aega, kui mind ühe vastamata kirja pärast, mis oli natukene hiljaks jäänud, haagikohtuniku, Salla mõisa härra von Harpe ette kutsuti aru andma," kirjeldab Liiv olukorda, millele järgneski luuletuse teemaks olev nädalapikkune arest (Liiv 1936: 74-75). 
tütar Leena Allik, kes lõpetanud suhte just noormehe vaesuse tõttu - polnud mõtet suhelda varatu renditaluniku pojaga (Kuningas 1960: 9). Seda õnnetut armastuslugu kirjeldab veel autor viimases luulekogus „Päikese veerul” ilmunud luuletuses „Unistused”, kus selgitatakse ka, et just südamevalu matmiseks otsustas noor luuletaja ülejäänud elu töö alla matta (Liiv 1933: 51). Seeria viimased värsid annavad mõista, et murtud südamega noormees kirjutas Leenile toona mälestuseks luuletusi, mis too ära põletas (Liiv 1933: 52):

Sa, Leeni, põletasid minu laulud, Mis oma kannatustest seekord lõin, Mis sulle viimseks mälestuseks tõin, Kus olid nähtavad mu hinge valud.

Ei enam sääraseid ma suuda luua,

Ei ole rinnas endist tundetuld, Et neid võiks uuesti veel ette tuua.

Nad rändasid kõik põlevasse ahju,

Nüüd kaebad sa, et sul on nendest kahju.

1875. aastal asus 16-aastane Jakob õppima Kodavere kihelkonnakooli, kus aasta hiljem sobiva õpetaja käe alla sattudes õppis tundma juba tõeliste poeetide loomingut. See innustas noormeest veel rohkem luulekunstile pühenduma. Tolleks õpetajaks oli Johann Jürgenstein, kirjanikunimega J. Lill, kelle tähtsust Liivi kujunemisele rõhutab ka luuletaja ise. Henrik Visnapuu leiab, et Jürgenstein ,juhtis andelise poisi juba alguses keele poolest õigele teele" (Visnapuu 1921: 77). Johann Jürgenstein asus Kodaverre koos vend Antoniga elama Jakob Liivi teisel õpiaastal 1876 - esimene õpetaja, teine õpilasena. ${ }^{13}$ Liivi hinnangul algas Jürgensteinide tulekuga nende koolis uus ajajärk, mis väljendus õpilastele kirjandusliku horisondi avamises (Liiv 1936: 39).

Nagu mitmetele teistele oma elus tähtrolli mänginud inimestele, kirjutab Liiv õpetaja Jürgensteinile hiljem tänutäheks soneti (Liiv 1900: 10):

\section{Tänuks}

Oma kooliõpetajale J. Jürgenstein-Lillele.

Sa andsid mulle õige Eesti meele

Ma selle eest veel nüüdgi tänan Sind.

Et laulan Eesti salus nagu lind

Seks painutasid lapsena mu keele.

Mind juhtisid siis armsalt tõe teele,

Kui paha poole painduv oli rind,

See on mu kõige kallim elu hind,

Silm, Sulle tänu andes, kipub meele.

Mu Elias, nüüd oled ära läinud -

Ei mitte taeva - minu silma eest.

Mu mõttes oled siisgi minu kõrgus.

13 Anton Jürgenstein (1861-1933), hilisem eesti kultuuritegelane: kirjanduskriitik, poliitiline publitsist, ajakirjanik. 
Ehk ammu pole ma Su palet näinud,

Su vaimu leian Sinu kirjadest.

Sest osake ka minu rinda nõrgus.

Jürgensteini tundides tutvus Jakob Liiv Lydia Koidula ja Ado Reinvaldi luulega, samuti loeti Kreutzwaldi loomingut - eelkõige „Rahunurme lilli” ja „Kalevipoega”, mida Liiv nimetabki „oma elusuuna määrajateks” (Liiv 1936: 46-47). Ka Kreutzwaldi surma puhul kirjutab Jakob Liiv soneti (värsimõõdult viisiktrohheuses, v.a kuues, 6-jalalises trohheuses värss) (Liiv 1891: 16):

\section{Isa Kreutzwald'i matuse päevaks}

1882

„Mine alla,” hüüdis Taeva-Isa

Oma valju surma inglile,

„Too see rahu nõudja ülesse

Ilmast, kus on vende valju kisa.

Pimeduse vaim, mis ilmas visa,

Selle vastu võidelnud ta vahvaste, -

Kandle mäng tal puhas kullane -

Minu koori sekka teda lisa."

Rahvas seisab leinates ja leskel -

Närtsinud on tähtjas sugutaim,

Hinge kandnud inglid paradiisi.

Istub kuulja laulikute keskel

Kallis Eesti lauluisa vaim,

Mängib muinast Viru laulu viisi.

Jürgenstein andis õpilastele palju lugeda ka saksakeelset luulet, iseäranis tugevat mõju avaldas Jakob Liivile romantiku Nikolaus Lenau (18021850) looming: „kõige rohkem äratasid vastukaja ta hinges Lenau laulud, kelle sügav ja kurb toon talle paistis olevat õige omane" (Kampmann 1933: 214-215).

Jürgensteini roll ei piirdunud oluliste teoste ja autorite tutvustamisega, Jakob leidis õpetajas ühtlasi vaimse kaaslase ja usaldusaluse, kellele saladuskatte all enda kirjutatud luuletusi näidata. ${ }^{14}$ Liiv meenutab: „Ma sain varsti temaga [Jürgensteiniga $-R$. L.] sõbraks ja usaldasin temale näidata oma salmikuid, mis varem olin sepitsenud. See jäi meie kahe saladuseks, ükski kolmas ei tohtinud sellest teada ega teadnudki. Selleks oli oma põhjus. Kui kaasõpilased talvel Peipsile liuglema läksid või kevadel Kirikuojal jääpanku alla lasksid, istusin mina klassis ja puurisin raamatute kallal, eriti saksa keelt

${ }^{14}$ Luuletamine polnud noorel Liivil ainult südameasi, vaid ühtlasi töö, mis võimaldas talle haridust - kuna tema isa kõiki kooliga seotud kulusid kanda ei saanud, teenis noormees raha juukseid lõigates, pitsereid tahvlikivvi või tinna lõigates, aga ka luuletades: „Raha eest aitasin külapoistel pilkelaule riimida, mis nad tüdrukute kohta tegid. Jürgensteini kirjatöödenõudmine aina suurendas minu sissetulekut. Oli ju õpilaste seas kõrtsmike ja kaupmeeste poegi, kes ei viitsinud või ei saanud kirjatöödega hakkama, need lasksid mind raha eest tööd mustalt valmis teha." (Liiv 1936: 45). 
õppides ja vahel ka salmikuid sepitsedes või oma Leenile kirja kirjutades" (Liiv 1936: 40-41).

Niisiis oli Jakob Liivil 1876. aastal Jürgensteinile juba mõni luulevihik ette näidata, õpetaja omakorda tutvustas poissi saksa(keelsete) poeetidega, sh juba mainitud Lenauga, keda Liiv ongi nimetanud esimeseks mõjutajaks sonettide kirjutamisel. „Lugesin Lenau sonette, need meeldisid väga. Tuli himu katsuda, kas ka eesti keel soneti välja annab. Alguses ei teadnud vormist suurt midagi, hiljem alles puutus näppu mingi saksakeelne teos, kus räägiti sonetist natuke pikemalt," on Liiv hiljem Kangrole selgitanud (Kangro 1938: 53). Kui Reinvaldist, Koidulast ja Kreutzwaldist sai Liiv inspiratsiooni eestikeelsele luuletamisele, siis vormilised eeskujud leidis ta saksakeelses luules.

Pinnas esimese soneti kirjutamiseks oli 1878. aastaks küps ning autori eluloo põhjal on selline dateering tõenäoline.

Esimesed luuletused avaldas Liiv 1880. aastatel ajalehtedes (nt Valguse lisaleht, Tartu Eesti Seitung, Eesti Postimees) pseudonüümiks $d r$ Toll, J. Doll, $d$-oll15, ka -ii- jt (vrd Vinkel 1959: 85). Elu jooksul ilmus Jakob Liivil kaheksa lüürilist luuleraamatut, esimene 1886., viimane 1933. aastal. Kokku leiab neis 107 sonetti, millest suurem osa ilmus mitmes luulekogus ning vahel mõningal määral muudetud või ka erineva pealkirja all (antud statistikas on korduvalt ilmunud, kuid pisikeste modifikatsioonidega sonetid loetud üheks). Värsimõõdult moodustavad enam kui pooled sonetid viisikjambid, esinemissageduselt järgnevad heteromeetrilised jambid, ligi kuuendik sonettidest on trohheuses, kolmikmõõtudest on esindatud amfibrahh ja daktül:16

$\begin{array}{lr}\text { J4 } & 2 \\ \text { J5 } & 61 \\ \text { J5/J4 } & 6 \\ \text { J5/J6 } & 15 \\ \text { T5 } & 10 \\ \text { T5/T6 } & 8 \\ \text { D4 } & 1 \\ \text { D5 } & 1 \\ \text { Am3 } & 1 \\ \text { Am4 } & 1 \\ \text { Am5 } & 1 \\ \text { Kokku } & 107\end{array}$

15 Tegu oli eneseiroonilise varjunimega, mille tagamaade kohta on kaks versiooni. Autor ise selgitab, et kuni kooli lõpuni nimetati teda „saksa mees Toll”, põhjuseks arvab ta olevat tõiga, et ta saksa keelt hoolega õppis. See ajendanud teda ka oma luuletusi kõigi teiste, v.a õpetaja Jürgensteini eest varjama: „Kui nad seda oleksid teadnud, et ma luuletasin, siis oleks pilge veel suurem olnud” (Liiv 1936: 41). Seevastu õpetaja noorem vend Anton Jürgenstein, kes nagu Jakobki õpilasperre kuulus, on seletanud nime tagamaid täpsemini: nad olla poistega 1878. aasta augustis Johann Jürgensteini tunnis lugenud Faehlmanni „Kriibus-kraabuse” nalja. „Jakobil oli ülesandeks õpetlase osa lugeda, kes tema juure sisse saadetud maamehele, kes ilmatarkuse raamatut „Kriibust-kraabust” nõudis, ütelda „Der Kerl ist toll”. Liiv tegigi seda nii suure andumusega, et sellega omale jäädava pilkenime „Dr. Toll” poiste seas ära teenis” (Jürgenstein 1929).

16 Statistikas on arvesse võetud luuletuse esmatrükk luulekogus; mõnel juhul on autor hilisemates redaktsioonides värsimõõtu ühtlustanud, muutnud nt üksiku 6-jalalise jambi 5-jalaliseks. 
Lisaks avaldas Liiv oma viimases luulekogus nn väikesi sonette, 9-realisi luuletusi, mis sünteesivad itaalia ja inglise sonetti, stroofiskeemiks $4+3+2$. Selliseid sonetoide leiame autori loomingust 20, sh üks 5-jalaline trohheus, üks 4-jalaline daktül, ülejäänud viisikjambid (vrd Liiv 1933: 48-52, kus on näiteks toodud „väike sonett” Leenile). ${ }^{17}$

Ei tohi ka unustada, et eesti keeles luuletamine polnud toona isegi eestlaste seas alati nii endastmõistetav kui saksa keeles. Nimelt kuna suurem osa kirjanduslikke eeskujusid pärines saksakeelsest kultuurist, tajuti sageli saksa keelt pigem kirjandusliku, samal ajal kui eesti keelt olmekeelena. Näiteks meenutab Valgamaalt Tarvastu kihelkonnast pärit Jakob Liivi põlvkonnakaaslane Martin Lipp (1854-1923), kelle 1883. aastal kirjutatud sonetid samuti eestikeelse soneti hällipõlve kuuluvad (Lipp 1883a; 1883b), ${ }^{18}$ oma luuletamise algusaega nii: „Kas ma ka juba mõne Eesti keelse algupärase laulu sel ajal [1877 ja $1878-R$. L.] olen luuletanud, ei tea ma mitte kindlasti ütelda. Kardan, et see mitte pole sündinud. Sest seda mäletan väga hästi: Eesti keele tarvitamine, kus ma aastate viisi Saksa hariduse mõju all olnud, tegi mul raskusi, kus asju tuli harutada, mis igapäevase elu piiridest üle läksivad. Ma ei olnud enam emakeele vaba isand" (Lipp 1910: 175).

Muidugi oli neid, kes eesti keeles luuletasid juba enne Liivi - kuid kui võtta võrdluseks Koidula või Kreutzwald, siis nende eluolud ning juurdepääs kirjanduse ja hariduse juurde erines väga suurel määral hariliku külalapse võimalustest. Erinevalt mitmest varasemast luuletajast pärines Jakob Liiv vaesest ja lihtsast perest ning isegi oma kihelkonnakooliõpingud pidi noormees oma taskust maksma. Kehv ligipääs raamatutele võiski jääda Liivi kui luuletaja üheks kammitsaks: tema kirjanduslik eruditsioon ei saanud olla kuigi ulatuslik, kuna tema töö- ja kodukoha lähedal puudusid korralikud raamatukogud, abiks ainult suhteliselt väikese säilikute arvuga Pandivere mõisa raamatukogu, hindab Oskar Kuningas. „Peame ühtlasi meenutama, et Liivi vaimse küpsemise aastail pakkus meie raamatuturg nii algupärase kui ka tõlkekirjanduse osas vähe edasiviivat," märgib kriitik (Kuningas 1960: 24).

Ometi kandis Jakob Liivi lakkamatu ja teadlik soov eestikeelset luulet arendada vilja ning Visnapuu nimetab just teda Bergmanni kõrval tähtsaimaks autoriks eesti luulekeele arendamisel, seda eriti varasema eestikeelse luule taustal. „Jakob Liivis on epigoonide salmiehitus ja sõnastus oma täiusele jõudnud," leiab Visnapuu ja lisab, et vanema Liivi tähtsus avaneb eriti siis, kui võrrelda tema luuletuste keelt Koidula, Kuhlbarsi või Kreutzwaldi omaga (Visnapuu 1921: 76-77).

17 Bernard Kangro uurimuses on märgitud Jakob Liivi sonettide koguarvuks 138 (Kangro 1938: 29), samal ajal ei selgita ta oma statistika põhimõtteid. Tõenäoliselt ei ole ta siia arvanud luuletusi, mida Jakob Liiv nimetab „väikesteks sonettideks”, kuivõrd tema sonetiajaloos pole neid mainitud. Ka perioodikas ilmunud luuletuste statistikasse lisamisel ei tule koguarvuks 138. Nii võib oletada, et kuna Liivil ilmus ligi 30 sonetti erinevates luuleraamatutes rohkemal või vähemal määral erinevate pealkirjade all, võis Kangro oma statistikas need erinevateks luuletusteks lugeda.

18 Martin Lipu ja juba esile toodud Bergmanni, Koidula ja Eiseni kõrval väärib 1880. aastate sonetistidest märkimist ka Elise Aun, samuti Georg Eduard Luiga, kelle noorpõlve jäävad üksikud, ent tähelepanuväärsed sonetid. 


\section{Rohkem kui luuletaja}

Just eesti keelele ja kirjasõnale pühendas Jakob Liiv teadlikult oma elu: lüürilise luule kõrval avaldab ta poeeme, kuulsaim neist „Vaimude org” (1906), ja näitemänge. Kuid see pühendumine ei väljendu Liivi puhul ainult ise luues. Luuletamine on individualistlik, enda sisemiste tunnete väljendamine reeglina üksinduses, ning ühtlasi autorluse ja autoriteediga seotud tegevus, kuid terve elu tegeles Jakob Liiv eesti keele ja kirjandusega ka ühiskondlikul tasandil. Autorile polnud tähtis üksnes oma kirjandusliku ambitsiooni rahuldamine, vaid ta tahtis panustada eestikeelsesse kirjasõnasse ka laiemas plaanis. Luuletamine oli üks väljund selle kõrgema eesmärgi täitmisel.

Nii pani ta 1882. aastal aluse ühele esimesele eesti luulerühmitusele, hiljem kirjandusloos Väike-Maarja Parnassiks nimetatud kooslusele. 1907. aastani tegutsenud rühmitusse kuulusid eri aegadel Peeter Jakobson, Jakob Tamm, Kaarel Krimm, Otto Münther ja Mihkel Kampmaa. Teisalt oli Liivi südameasjaks laste ja noorte kirjanduslik haritus. Ida Esinurm kirjeldab, kuidas Jakob Liiv venestusajal juba ise viie lapse isana ka ümbruskonna lastele eesti keelt õpetas, hoidis koos abikaasa Rosaliega koduuksed lahti ja pidas võõraid lapsi nagu enda omadeks, õpetades neile eesti keelt, riimimist, jutustamist. See oli seda olulisem, et Narva gümnaasiumis eesti keelt ei õpetatud. „Õhtuti kogunesime vahel ahju lähedale tema juurde, siis jutustas ta meile lugusid, laskis neist ümberjutustusi teha ja pärast parandas neid. See oli tal kohe mureks, et meie ka eesti keelt ja kirjandust tundma õpiksime. Kui ilmus midagi uut, siis tõi ta need raamatud meile lugeda," meenutas ta (Esinurm 1954: 5-6).

Nii sai Jakob Liiv ka mitme tulevase luuletaja esimeseks lugejaks ja nõuandjaks. Poetess Kersti Merilaas (1913-1986), kelle mälestustes oli Liivide maja neile kui teine kodu, näitas enda sõnul oma luuletusi alati esmakorras talle, ning sai tihti tulusaid õpetussõnu. Merilaas meenutab, et peaaegu eranditult noored moodustasidki Liivi igapäevase sõprusringi ning kaasaegne kultuur köitis Liivi surmani - tal oli uuema aja kirjanduse vastu elav huvi ja terav pilk (Merilaas 1938: 92). Aega veedeti lõbusalt korraga raamatute ja märjukese seltsis. „Veini oli Liivil alati tõhus tagavara. Käisime siis hulgakaupa abis marju korjamas ja pressivänta keerutamas. Liivi aia marjadest jätkus veiniks mitmele perele," meenutab Merilaas (1938: 95).

Sellised kirjeldused ei haaku Jakob Liivi kui elukibeda mehe kuvandiga, mis osalt võib olla tekkinud tema mõnest valulise tooniga luuletusest. Vend Juhani heroiline positsioon eesti kultuuriloos - vastupidi üsna karmile kriitikale, mida Jakob Liivi luule pälvis - näitas talle eriti teravalt kätte tema koha. Nii oli ta ohates Kersti Merilaasile tunnistanud: „Jah, olen suure vennana väikene vend," lisades, et teda ei maksa üldse kirjanikuks nimetada, vaid kõigest asjaarmastajaks võib teda pidada, „nokitsen niisama muu töö kõrval". Ent see ei olnud põhjus kibestumiseks, eelkõige muserdas luuletajat tõsiasi, et tema noorem vend Juhan pidi haiguse ajal armetuis tingimusis ja üksinduses olema, hiljem - nagu vend Jakob väljendab - lõigati aga sama haiguse pealt profiiti (Merilaas 1938: 92). ${ }^{19}$

19 Sama mõtet väljendab ka sonett „Oma venna Juhan Liivi 10-a. surmapäeva puhul”: „Heidetud hilbud ja hinnata iva / Kattis sind, vaigistas nälga ja jänu: / Kerjakott kaalus su väärtust ja hinda. // Kiituse kõla ja hiline tänu / Kannab su hauale sambaks nüüd kiva / Rõhuma haudagi rõhutud rinda" (Liiv 1929: 339). 


\section{Kokkuvõtteks}

Jakob Liivi luule algab ja lõpeb sonetiga. Luuletaja esimese luulekogu „WiruKannel I" avab luulele pühendatud sonett (Liiv 1886: 4):

\section{Luulele}

Sa kihlad maaga kokku kõrge taeva Ja lendad vabalt läbi ilmamaa:

Oh võta minu hinge ühes rändama, Ja laena t'ale aset oma laeva!

Su vallas unustan siis elu vaeva, $\mathrm{Su}$ onnist healt ma ihkan kuulata, Ja sinu nurmelt tahan õisi noppida Mis pärjaks punun armsamalle kaela.

Su kõne nagu kannel pühast ilmast Kui vägev kõne - magus armu heal. Kes sind ei tunne jäävad ikka kurdiks.

Ei kustu sinu ilu minu silmast.

Sa tähe läitel vaimu taeva peal - Oh tule mulle paleuste pruudiks!

Koonus, 26. detsembril 1885

Sonett, mida on peetud autori suurimaks õnnestumiseks, on armastusluuletus, mis on suunatud ühtaegu nii kallimale kui ka luulele endale: kui avavärssides on luule midagi, mis ühendab ühtaegu maad taevaga ja mind armsamaga, siis lõpuvärsis palub luuletuse mina juba luulet ennast omale „paleuste pruudiks”. Ülevas toonis kirglik sonett vaatab ootusrikkalt ühise tuleviku poole.

Jakob Liivi suhe luule ja sonettidega kestabki tema viimaste eluaastateni ning seda teekonda iseloomustab ühtaegu katkematu pühendumus ja pidevad kahtlused, kas mina on vääriline luuletaja. Raamatu „Lüürilised laulud” lõpetab ta luuletusega „Lõppsõna”: „Plaksutage, kui kord lasete mind hauda! / Siin on minu lõpp-komöödia... / Näitelavalt astub vaikselt alla / Narriosa etendaja näitleja” (Liiv 1929: 360). Järgneb Jakob Liivi viimane luulekogu „Päikese veerul”, mille eelviimaseks luuletuseks on samuti sonett. Siingi mõtestab mina - nüüd juba läbitud - oma luuleteed (1933: 75):

\section{Epiloog}

Kui erak, - kes ei vaja heldeid südameid,

Ei matka läbi kaugeid võõraid maid,

Ei kiida roomajaid, ei austa vägevaid, -

Ma käisin vaikselt üksiklase teid. 
Mul polnud palju sõpru, polnud vaenlaseid,

Ei juhatajaid ega juhtijaid.

Ma töödele ei otsind kiitvaid kriitikaid:

Kõik olge tänatud, kes laitsid neid!

Mind kiitus oleks teinud uhkeks, upsakaks,

Ma oleksin kui ebageenius,

Kes suur on ainult oma kuju ees.

Kuid võitlus iga vaenlasega tugevaks

Mind oleks teinud, ja mu tegevus

Vist paistaks hoopis teises valguses...

Jälle kõlab luuletaja igavene kahtlus endas kui luuletajas, mis läbib nii kogu autori loomingut kui ka seda saatvat kriitikat, samuti tema igavene pühendumine luulele. Jakob Liivi suhe luuletamisse ja sonettidesse on ühtaegu isiklik, kuid samal ajal teadlikult kultuurilist mõõdet omav. Liivi jaoks on sonett luule par excellence, sonetivormi toomine eestikeelsesse luulesse ning meisterliku soneti loomine eesti keeles tähendab tema jaoks eesti luule paigutumist lääne luulekultuuri. Omaette huvitav küsimus on Liivi loodud „väikesed sonetid" (nagu autor ise neid nimetab) - stroofiskeemiga 4+3+2, peamiselt 5-jalalises jambis, mille struktuur sünteesib inglise ja itaalia sonetti -, pakkudes muuhulgas suurepärast analüüsimaterjali erinevuse kaudu soneti kanoonilise vormi mõtestamiseks. Rikkalik sonetilooming, mis Jakob Liivi esimeste ja viimaste sonettide vahele jääb, k.a mainitud leiutatud sonetoidid, vajavad aga eraldi analüüsi ja artiklit.

William K. Matthews märgib, et Jakob Liiv on „temast kuulsama ja õnnetuma Juhani” vanem vend (1946: 160). Ennekõike väärib Jakob Liiv tuntust eesti värsikultuuri arendajana, kes hakkas juba 1880. aastate künnisel sihikindlalt nõudlikku sonetivormi eesti keelde istutama ning jätkas seda tööd kuni surmani. Ühtlasi võib Jakob Liiv olla esimeste eestikeelsete sonettide autor: 1902. aastal ilmunud kogu „Wiru-Kandle I. jagu” täiendatud kordustrükis märgitud aastaarv soneti „Isale” all nihutaks eestikeelse soneti sünni praegu teadaolevast kolm aastat varasemasse aega, 1878. aastasse, ${ }^{20}$ ning tema sonett „Asjata” on dateeritud Eiseni omast varasema aastaarvuga. Siiski tuleb nentida, et peale autori enda hilisemates redaktsioonides lisatud dateeringute ei ole tõendeid, et Jakob Liiv tõepoolest need sonetid 1878. ja 1880. aastal kirjutas. Tuleb arvestada sedagi, et isegi kui kõnealused sonetid nimetatud aastatel on kirjutatud, pole võimalik kindlaks teha, kui palju ta enne avaldamist neid parandas ja muutis.

20 Miks jääb see märkimata või märkamata Bernard Kangrol (jt värsiuurijatel), on omaette küsimus. Kangrol olnuks ka oma monograafia kirjutamise ajal võimalus nende sonettide daatumite kohta Jakob Liivilt aru pärida. Samas võiks eeldada, et kui ta oleks selle küsimusega tegelenud, oleks ta oma töös selle ka ära märkinud isegi juhul, kui jõudnuks mingil põhjusel järeldusele, et need kuupäevad ei saa olla õiged. Ehkki Kangro tegi väga hoolsat tööd varasemate sonettide otsimisel, vaadates läbi kõik luulekogud, ajalehed, ajakirjad jm väljaanded, võisid kordustrükis sonettidele lisatud kuupäevad tal lihtsalt kahe silma vahele jääda. Kuna Kangro emigreerus üsna pea pärast uurimuse avaldamist Rootsi, ei pruukinud ta kõnealuste Jakob Liivi sonettidega enam hilisemas elus kokku puutuda. Mõistagi ei saa välistada sedagi, et nende sonettide daatumitest vaikimine oli Kangro teadlik otsus, nt võis ta välistada nende kirjutamise märgitud aastatel. 
Mõlemad luuletused on juhusonetid, seotud konkreetse tähtpäeva või sündmusega; mõlemad sündmused on ajas määratletavad. Kuigi Jakob Liiv sageli dateeris oma luuletusi, leidub palju neidki, millel puudub aastaarv või kuupäev, seejuures mitmed esimeses „Wiru-Kandles” (1886) ilmunud. Võib oletada, et autor ei saanud tagantjärele paljude luuletuste puhul õiges kuupäevas kindel olla, küll aga oli see võimalik konkreetsete sündmustega seotud sonettide puhul. ${ }^{21}$ Sonettide „Isale” ja „Asjata” dateeringuid toetavad autori eluloolised andmed - 1876. aastal Johann Jürgensteini õpilasena pidas noor luuletaja oma suurimaks eeskujuks Lenaud, kelle loomingus on sonetil oluline koht. Samuti on teada, et Jakob Liiv oli toona juba aastaid luuletanud ning näitas oma loomingut ka õpetaja Jürgensteinile.

Kuigi nii „Isale” kui ka „Asjata” dateeringud jätavad õhku küsimusi, ei saa siiski mööda vaadata tõsiasjast, et on sonette, mille trükis avaldatud dateeringud tõstavad need Eiseni sonetist ajaliselt ettepoole ehk esimesteks eestikeelseteks sonettideks.

\section{Arhiivimaterjalid}

Es in u rm 1954. Mida ma mäletan Väike-Maarja kolmest laulikust. - KM EKLA, koopiad 193: 12.

Li i v, Jakob. - KM EKLA, f 68, m $8: 1$.

Li i v, Jakob. - KM EKLA, f 18, m $79: 1$.

L i p p, Martin 1910. Minu elumälestused I. Noorest põlvest kuni aastani 1910. KM EKLA, f 80, m $29: 1$.

\section{Kirjandus}

A a vi k, Johannes 1929. Jakob Liiv. Elu. - J. Liiv, Lüürilised laulud. Tartu: Eesti Kirjanduse Selts, lk 7-18.

B r o ck m a n n, Reiner 2000. Teosed. Koostanud ja toimetanud E. Priidel. Tartu: Ilmamaa.

E i s e n, Matthias Johann (koost) 1881. Eesti luuletused. Tartu: Schnakenburg.

H irv, Indrek 2000. Ööpäev. Luulet 24 aastast tõlgete ja lehejuttude taustal. Tallinn: Virgela.

J õ g e ve r, Jaan 1907. Uued raamatud. - Eesti Kirjandus, nr 1, lk 25-31.

J õ g e v e r, Jaan 1910. Jakob Liivi kirjatööd. II anne. Laulud ja lugulaulud. - Eesti Kirjandus, nr 4, lk 161-163.

J ü r g e n s t e i n, Anton 1929. Der Kerl ist toll. Mälestus Jakob Liivi koolipõlvest.

Postimees 2. II, nr 60.

K a m p m a n n, Mihkel 1933. Jakob Liiv. - Eesti kirjandusloo peajooned. Teine jagu. Näidete varal seletanud M. Kampmann. [Kolmas, ümbertöötatud ja kirjandusteaduse uuematele seisukohtadele kohandatud trükk]. Tartu: Eesti Kirjanduse Selts, lk 213-222.

K a n g r o, Bernard 1936. Mõni sõna esimestest eesti sonettidest. - Eesti Kirjandus, nr 6, lk 269-272.

21 Käesoleva artikli tarvis on tutvutud Kirjandusmuuseumis asuvate Jakob Liiviga seotud säilikutega: nii tema luuletuste käsikirjade, kirjavahetuste kui ka teiste kirjadega, kuid informatsiooni esimeste sonettide kirjutamise kohta ma sealt ei ole leidnud. 
K a n g r o, Bernard 1938. Eesti soneti ajalugu. Akadeemilise Kirjandusühingu toimetised. Tartu: Akadeemilise Kirjandusühingu kirjastus.

K o i d u l a, Lydia 1969. Luuletused. Tekstikriitiline väljaanne. Koost E. Aaver. Tallinn: Eesti Raamat.

Kr e u t z w a l d, Friedrich Reinhold 1953. Laulud. Tallinn: Eesti Riiklik Kirjastus.

K u n ing a s, Oskar (koost) 1960. Jakob Liivi elust ja loomingust. - J. Liiv, Valitud teosed. Tallinn: Eesti Riiklik Kirjastus, lk 7-37.

L e pik, Mart 1961. Järelmärkus [Kristian Jaak Petersoni luuletustele Betti Alveri tõlkes]. - Looming, nr 7, lk 1047-1048.

L i i v, Jakob 1886. Wiru-Kannel. I. jagu. Luuletanud Jakob Liiw. Tallinn: M. Leppik.

L i i v, Jakob 1891. Wiru-Kannel. 2. anne. Jakob Liiw'i Laulud. Rakvere: N. Erna.

L i i v, Jakob 1894. Leina-lilled. Kimbuks köitnud Jakob Liiw. Jurjew: K. A. Hermann.

L i i v, Jakob 1900. Wiru-Kannel. 3. anne. Jakob Liiw’i Laulud. Tallinn: Uus Aeg.

L i iv, Jakob 1902. Jakob Liiw'i laulud. Wiru-Kandle I. jagu. Teine, täiendatud trükk. Rakvere: N. Erna.

Li i v, Jakob 1906. Jakob Liiw'i kirjatööd. 1. anne. Laulud. Tartu: Postimees.

L i i v, Jakob 1910. Seletuseks. - Eesti Kirjandus, nr 6, lk 269-270.

L i i v, Jakob 1929. Lüürilised laulud. Tartu: Eesti Kirjastuse Selts.

L i i v, Jakob 1933. Päikese veerul: 1929-1934. Rakvere: J. Liiv.

L i i v, Jakob 1936. Elu ja mälestusi. Tartu: Noor-Eesti.

L i i v, Jakob 1960. Valitud teosed. Koost O. Kuningas. Tallinn: Eesti Riiklik Kirjastus.

L i p p, Martin 1883a. Hallikas. Oleviku lisaleht, nr 9, 28. II.

L i p p, Martin 1883b. Ära nuta. Oleviku lisaleht, nr 15, 27. IV.

L o t m a n, Maria-Kristiina, L ot m a n, Mihhail 2007. Eesti silbilis-rõhulise neljajalalise trohheuse rõhustruktuurist. - Keel ja Kirjandus, nr 2, lk 116-142.

L u i g a, Georg Eduard 1882. Eestimaale. Valguse lisaleht 11. VIII.

M a t t h e w s, William Kleesman 1946. Estonian Sonnet. - The Slavonic and East European Review, Vol. 25, No. 64 (Nov.), lk 159-170.

M e r i l a a s, Kersti 1938. Mälestusi Jakob Liivist. - Looming, nr 1, lk 92-95.

M ä g e r, Mart 1986. Sada aastat Eesti sonetti. - Sajandi sada sonetti. Koost M. Mäger. Tallinn: Eesti Raamat, lk 6-11.

O r a s, Ants 1966. Eestimaalase Jaak Petersoni luulet. - Tulimuld, nr 2, lk 66-67.

Peterson 1823 = Gedichte des Esthländers Jaak Petersohn. Zeitung für die elegante Welt. 26. III, nr 57, veerud 453-454. Leipzig.

P e t e r s o n, Kristian Jaak 1961. [Betti Alveri tõlked saksakeelsetest luuletustest Mart Lepiku järelmärkusega]. - Looming, nr 7, lk 1046-1048.

P e te r s o n, Kristian Jaak 1976. Laulud. Päevaraamat. Toim K. Taev. Tallinn: Eesti Raamat.

P õ l d m ä e, Jaak 1978. Eesti värsiõpetus. Tallinn: Eesti Raamat.

R o o s, Jaan 1938. Jakob Liiv surnud. - Eesti Kirjandus, nr 2, lk 65-68.

U n d u s k, Jaan 2001. Kristian Jaak Peterson. Kommentaare eluloodaatumeile. - IAAK. Kristian Jaak Peterson 200. Eesti Keele Instituut, Underi ja Tuglase Kirjanduskeskus. Tallinn: Eesti Keele Sihtasutus, lk 13-20.

Vi n k e l, Aarne 1959. Jakob Liivi tulek kirjandusse. (Kirjaniku 100. sünni-aastapäevaks.) - Keel ja Kirjandus, nr 2, lk 85-91.

V i s n a p u u, Henrik 1921. Vanad ja vastsed poeedid. Tartu: Noor-Eesti. 
Keywords: Jakob Liiv, Estonian sonnet, 19th century, Estonian literary history

According to Bernard Kangro's Eesti soneti ajalugu („History of the Estonian sonnet”, 1938) the first Estonian sonnet ever written was Õnnesoov isamaale („Congratulation to Fatherland”) by Matthias Johann Eisen, published in 1881, which has ever since been regarded as the birth year of the Estonian sonnet.

However, there are two Estonian sonnets dated to earlier years by their author Jakob Liiv (1859-1938). The sonnet Isale 50 aastaseks sündimise päevaks („To Father on his 50th anniversary”) bears the date 1878, and Asjata („In vain”) 1880. Both were published later than Eisen's poem: Isale... in 1886 (undated) and 1903 (dated), while Asjata was published even later. The problem is whether Jakob Liiv actually wrote the sonnets in those years, which would mean a threeyear prolongation of the history of the Estonian sonnet. To find an answer, the two sonnets are first analysed from the aspect of the technique of verse (metre, rhyme) in the context of the period as well as Liiv's oeuvre, after which the two are referred to the author's biographical background. The article fails to provide a definitive answer, though.

The biographical data seem to support Liiv's own datings, as by 1878 the young Liiv had been practising poetry for several years, also showing the results to his teacher Johann Jürgenstein. In addition, he was already acquainted with the oeuvre of Nikolaus Lenau, whose poetry, especially the sonnets, has been pointed out by Liiv as an influential example. Questions can be raised, however, about the technique of verse. Asjata, for example, is the only amphibrach in Liiv's early oeuvre, moreover, the rhyming technique used is also more characteristic of the mature Liiv. Possibly, the truth is somewhere in the middle: Jakob Liiv may indeed have written those sonnets as dated, but edited them thoroughly before publishing.

Rebekka Lotman (b. 1978), MA, University of Tartu, Institute of Cultural Research and Fine Arts, doctoral student, managing editor at Tallinn University Press, rebekka.lotman@tlu.ee 